\title{
Zum Wechsel in der Herausgeberschaft der Zeitschrift für Psychodrama und Soziometrie
}

Unsere Kollegin, Dr. med. Ulrike Fangauf, hat ihre langjährige Tätigkeit als Herausgeberin der ZPS im Mai 2010 beendet und hört auch mit ihrer Tätigkeit als Redaktionsmitglied im November 2010 auf.

Ulla war seit 1990 Mitglied der Redaktion der von Ulf Klein und Reinhard Krüger gegründeten Zeitschrift „Psychodrama“ im InScenario-Verlag, die 2001 unter dem neuen Namen „Zeitschrift für Psychodrama und Soziometrie“ zu Leske \& Budrich wechselte, der vom VS-Verlag übernommen wurde. Es gäbe die Zeitschrift vermutlich nicht mehr, wenn Sie nicht diese Übergänge virtuos gemanagt hätte.

Ullas Abschied schmerzt. Denn wir sind mit ihr zum Teil in langer Zusammenarbeit durch viele Einigungsprozesse aber auch Konflikte gegangen und haben eine ganze Zahl von problematischen Situationen gemeinsam gemeistert, zuletzt auch einen relativ großen Umbruch im Team der Redaktionsmitglieder.

Ulla war als Herausgeberin der Zeitschrift ab 2001 zusammen mit Franz Stimmer und ab 2008 zusammen mit Christian Stadler das zentrale Bindeglied (manchmal auch der Prellbock) zwischen dem Verlag und den AutorInnen, den Redaktionsmitgliedern und den AbonnentInnen und hat als solches intensiv, mit hohem Engagement, großem Organisationstalent und viel Erfolg vermittelt und sich für die Zeitschrift eingesetzt. Die ZPS ist in dieser Zeit zu einer der international angesehensten Psychodrama-Zeitschriften geworden. Auch hat Ulla die innere Organisation der ZPS strukturiert, dafür gesorgt, dass die Zeitschrift in guter Qualität zuverlässig erscheint und dabei immer wieder die Essentials der Fachzeitschrift hervorzuheben gewusst.

Neben Ihrer Herausgebertätigkeit hat Ulla sich auch durch die redaktionelle Herausgabe vieler Themenhefte der ZPS verdient gemacht, wie „Wirkfaktor Gruppe“ (Heft 1, 2002) „Kreativität wagen“ (Heft 2, 2003), „Sucht“ (Heft 2, 2004 mit Michael Zwilling), „Junge PsychodramatikerInnen“ (Heft 1/2006 mit Christian Stadler) „Körper“ (Heft 1, 2008 mit Christian Pajek) und „Tele, Beziehung“ (Heft 2, 2010 mit Christoph Hutter).

Wir bedauern das Ausscheiden von Ulla aus unserem Kreis sehr und werden ihr Wissen, ihren Mut und ihre Erfahrungen vermissen. Wir werden versuchen, die Zeitschrift in ihrem Sinne weiter zu führen.

Manfred Gellert im Namen der RedaktionskollegInnen

Online publiziert: 03.08 .2010

(C) VS Verlag für Sozialwissenschaften 2010 